\title{
¿SE HABRAN INTERPRETADO MAL LOS RESULTADOS DE LA TERAPIA CON GONADOTROPINA MENOPAUSICA HUMANA?
}

\author{
Dr. Walter W. Williams, M.D.
}

20 Magnolia Terrace. Springfield, Massachusetts.

La percepción popular del valor clínico de la gonadotropina menopáusica ("GMH") es considerablemente distorsionada por la disposición de los datos que se presentan en diversos informes de investigaciones que tratan sobre la inducción de la ovulación. Tales informes tienen por objeto difundir el uso de la GMH en lugar de divulgar los resultados clínicos reales, y los hechos se oscurecen en medio de datos que son ajenos o desorientan. La medida verdadera del valor de la GMH consiste en el aumento de la proporción de gestaciones normales, el costo para los pacientes en términos de gestaciones normales y la incidencia de morbilidad considerable. Teniendo en cuenta esos factores, las datos de uno de los informes han sido dispuestos en tal forma que indican más claramente los resultados finales. Se hace notar que las opiniones relativas al valor de la terapia con GMH ha sido por lo general basado en demasiadas opiniones, o sobre los resultados de unos pocos casos en los cuales se ha tenido éxito y que han sido ampliamente publicados en la prensa civil y médica.

\section{CUADRO NN 1}

PROPORCIONES DE CONCEPCIONES Y DURACION TOTAL DE GESTACIONES DESPUES DE TERAPIA CON GMH EN LAS SERIES CUTTER-THOMPSON

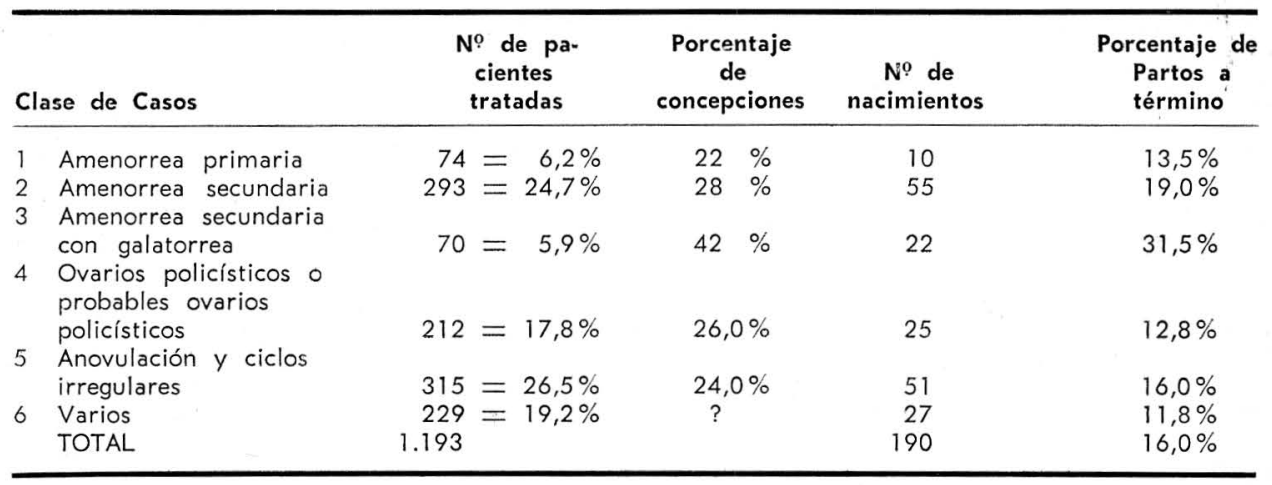


El Cuadro 1 muestra la proporción de concepciones de los diferentes grupos clínicos reportados por la serie de Laboratorios Cutter - Thompson $(1,2)$. El informe sobre esta serie representa el principio básico para la explotación comercial de la GMH. La lectura de los numerosos informes sobre la terapia con GMH revela que muy pocos de los pacientes tratados han presentado mejoría en su defecto pituitario. Gemzell informó sobre una incidencia de aproximadamente un 5\% (3). Por tanto, gran parte de la terapia en muchas series de investigación se considera meramente empírica. Puesto que no se utilizan los controles clínicos, la proporción de concepciones correctamente atribuíbles a la terapia es simplemente presuntiva.

El Cuadro 2 muestra el costo de la terapia con GMH en las series de Laboratorios Cutter - Thompson, el cual aparentemente es representativo de otros grupos de investigación en los Estados Unidos. Es evidente que los resultados presentados en los Cuadros 1 y 2 no están de acuerdo con las creencias generales sobre la gran efectividad de esta terapia; pero estos factores difieren de los datos originales únicamente en su disposición, de tal manera que bien puede uno percibir más claramente los resultados finales reales. Un análisis clínico o una evaluación de los datos presentados en muchos otros informes sobre investigaciones sobre la inducción de la ovulación, muy posiblemente producirán una percepción diferente de los resultados finales de la que se obtendría de la lectura rápida de estos informes debida principalmente a las diferencias en el criterio de diagnóstico sobre el cual prescribió la terapia.

Desafortunadamente, algunos periódicos que tratan los diferentes as-
Rev. Col. Obst. y Ginec.

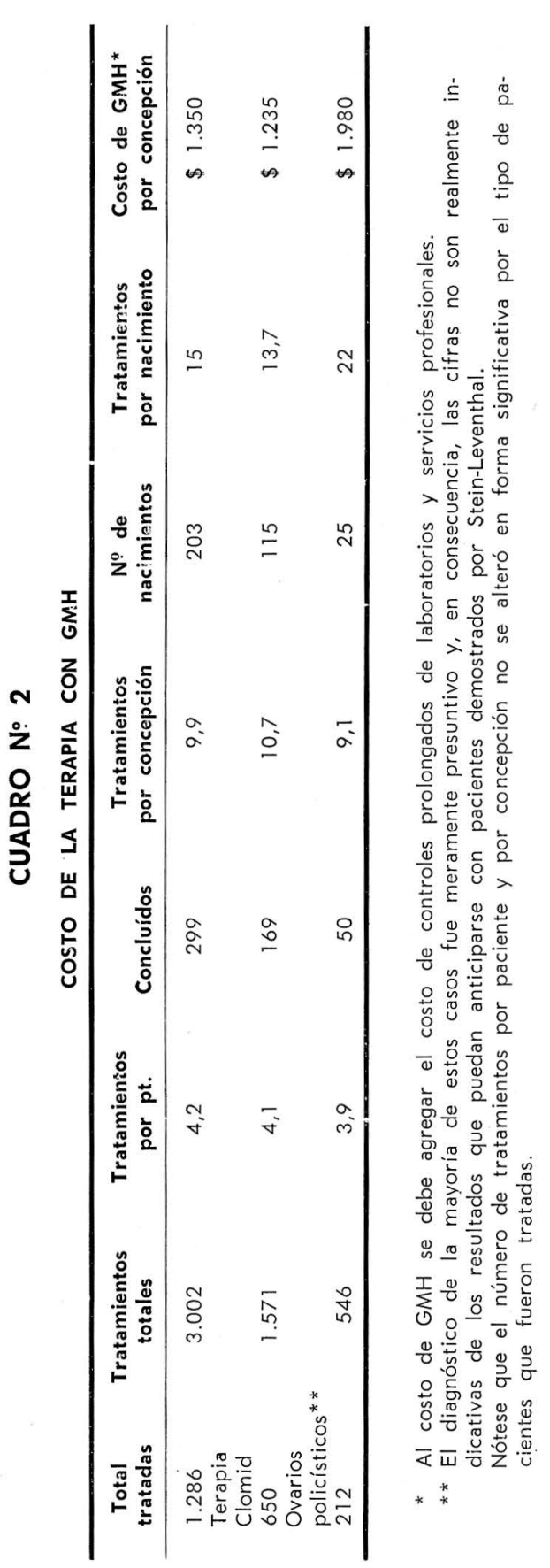


pectos del problema de la reproducción, incluyendo publicaciones importantes sobre ginecología, endocrinología y fertilidad, limitan sus páginas únicamente a la publicación de investigaciones nuevas y originales que son aceptadas por su valor intrínseco, asegurando así la perpetuidad de muchas creencias y prácticas falsas que surgen de la investigación defectuosa.

\section{BIBLIOGRAFIA}

1 THOMPSON, CHARLES R. Y HANSEN, LAURA M. Pergonal (menatropinas). Un Resumen de las Experiencias Clínicas sobre Inducción de Ovulación, Fertilidad y Esterilidad. 21 (12): 844-853, 1970.

2 Laboratorios Cutter. Tratamiento de la infertilidad femenina con Pergonal (menatropinas). Información sobre el producto. Publicación de Laboratorios Cutter, 1970.

3 GEMZELL, CARL. Inducción de la Ovulación con Gonadotropinas Humanas. Int. J. Obstet. \& Gynaec. 8 (4): 593-599, 1970. 